\title{
ANALISIS DETERMINAN PENGANGGURAN DI KABUPATEN NUNUKAN
}

\author{
ANALYSIS UNEMPLOYMENT DETERMINANT IN NUNUKAN DISTRICT
}

\author{
Andi Hermawan', Asih Kusuma Wijayanti ${ }^{2)}$ \\ (Universitas Borneo Tarakan) \\ Email: andihermawan090995@gmail.com, \\ yantimiracle@gmail.com
}

\begin{abstract}
Abstrak: Tujuan penelitian ini adalah untuk Menganalisis hubungan antara pendidikan, pertumbuhan penduduk, dan Upah Minimum Kota (UMK) dengan pengangguran di Kabupaten Nunukan. Penelitian ini menggunakan pendekatan kuantitatif,Jenis data yang digunakan yaitu data sekunder, berupa data angka pengangguran, pendidikan, pertumbuhan penduduk, dan upah minimum kota yang diambil dari Badan Pusat Statistik (BPS) Kabupaten Nunukan. Data yang diperoleh diolah menggunakan aplikasi EViews versi 8.0.

Berdasarkan hasil perhitungan korelasi maka diperoleh hasil hubungan antara pendidikan pada tahun 2008-2015 di Kabupaten Nunukan dengan tingkat pengangguran tahun 20082015 di Kabupaten Nunukan adalah -0.473394 dengan tingkat keeratan hubungan kategori cukup dan bentuk hubungannya adalah linier negatif. Hubungan antara pertumbuhan penduduk pada tahun 2008-2015 di Kabupaten Nunukan dengan tingkat pengangguran tahun 2008-2015 di Kabupaten Nunukan adalah -0.280480 dengan tingkat keeratan hubungan kategori lemah dan bentuk hubungannya adalah linier negatif. Hubungan antara Upah Minimum Kota pada tahun 2008-2015 di Kabupaten Nunukan dengan tingkat pengangguran tahun 2008-2015 di Kabupaten Nunukan adalah -0.685944 dengan tingkat keeratan hubungan kategori kuat dan bentuk hubungannya adalah linier negatif.
\end{abstract}

Kata Kunci : Pendidikan, Pertumbuhan Penduduk, Pengangguran, dan UMK.

Abstract: The purpose of this research was to analyze the relationship between education, population growth, and City Minimum Wage (CMW) with unemployment in Nunukan District. This research uses a quantitative approach The type of data used is secondary data, are unemployment, education, population growth, and city minimum wage data taken from Central Berau of Statistics (BPS) of Nunukan district. The data obtained is processed using EViews application version 8.0.

Based on the results of correlation calculations obtained the relationship between education in 2008-2015 in Nunukan District with unemployment rate in 20082015 in Nunukan District is -0.473394 with the level of closeness of the relationship enough category and the form of the relationship is negative linear. The relationship between population growth in 2008-2015 in Nunukan District with unemployment rate in 2008-2015 in Nunukan District was 0.280480 with the level of closeness of weak category relations and the relationship form was negative linear. The relationship between City Minimum Wage in 2008-2015 in Nunukan District with unemployment rate in 2008-2015 in Nunukan District is -0.685944 with strong closeness relationship level and relationship form is negative linear.

Key Word: Education, Population Growth, City Minimum Wage (CMW), Unemployment. 


\section{LATAR BELAKANG}

Berdasarkan UU No. 25 tahun 2004 sistem Perencanaan Pembangunan Nasional, dijelaskan mengenai Rencana Pembangunan Jangka Menengah Nasional (RPJM Nasional). Dalam pelaksanaan RPJM Nasional, dikenal adanya strategi pokok pembangunan yang salah satunya memuat tentang strategi pembangunan Indonesia. Sasaran pokok dari strategi pembangunan Indonesia adalah untuk memenuhi kebutuhan hak dasar rakyat serta menciptakan landasan pembangunan yang kokoh. Hak-hak dasar rakyat yang dimaksud adalah dalam bentuk bebas dari kemiskinan, pengangguran, keterbelakangan, ketidakadilan, penindasan, rasa takut, dan kebebasan mengemukakan pemikiran dan pendapat memperoleh prioritas untuk diwujudkan. Indonesia merupakan salah satu negara berkembang, dalam pengelompokan negara berdasarkan taraf kesejahteraan masyarakat, dimana salah satu permasalahan yang dihadapi oleh negara berkembang termasuk Indonesia adalah masalah pengangguran.

$\begin{array}{ccc}\text { Pengangguran merupakan masalah } \\ \text { yang } & \text { sangat kompleks karena }\end{array}$ mempengaruhi sekaligus dipengaruhi oleh beberapa faktor yang saling berinteraksi mengikuti pola yang tidak selalu mudah dipahami. Apabila pengangguran tersebut tidak segera diatasi maka dapat menimbulkan kerawanan sosial dan berpotensi mengakibatkan kemiskinan (BPS, 2007). Gejala pengangguran yang terselubung di daerah dan di lingkungan kota sebagian akibat dari kurang tersedianya lapangan kerja yang produktif penuh, yang membawa hasil kerja, nafkah, dan mata pencaharian yang memadai untuk memenuhi kebutuhan dasar. Indonesia masih dihadapkan pada dilema kondisi ekonomi yang tidak seimbang antara internal dan eksternal, ketidakseimbangan internal terjadi dengan indikator bahwa tingkat output nasional maupun tingkat kesempatan kerja di Indonesia tidak mencapai kesempatan kerja penuh (Boediono, 1993). Pengangguran yang terjadi di daerah dan lingkungan kota maupun kabupaten merupakan akibat dari tingginya tingkat perubahan angkatan kerja yang tidak diimbangi dengan adanya lapangan kerja yang cukup serta penyerapan tenaga kerja yang cenderung kecil presentasinya, hal ini disebabkan oleh rendahnya tingkat pertumbuhan terciptanya lapangan kerja untuk menampung pekerja yang siap bekerja.

Kabupaten Nunukan adalah 1 dari 5 Kabupaten/Kota yang ada di Kalimantan Utara Provinsi termuda di Indonesia, Permasalahan yang terjadi di Kabupaten Nunukan yakni angka pengangguran yang mengalami fluktuatif yaitu angka pengangguran yang masih naik turun. Seperti data dari Badan Pusat Statistik (BPS) 2017 Kabupaten Nunukan 8 tahun terakhir memperlihatkan angka pengangguran pada tahun 2008 mencapai $13,17 \%$, lalu mengalami penurunan ditahun 2009 dan 2010 menjadi 7,67\%, tetapi pada tahun 2011 mengalami kenaikan sebesar $13,14 \%$, dan pada tahun 2012, 2013, 2014, dan 2015 menurun menjadi $3,78 \%$.

\section{RUMUSAN MASALAH}

Berdasarkan uraian yang dipaparkan di atas, penulis tertarik untuk meneliti korelasi Pendidikan, Pertumbuhan Penduduk, dan Upah Minimum Kota dengan Pengangguran di Kabupaten Nunukan. Penulis melakukan penelitian dengan judul "Analisis Determinan Pengangguran Di Kabupaten Nunukan".

\section{TUJUAN PENELITIAN}

Berdasarkan latar belakang dan permasalahan yang dikemukakan, maka tujuan yang ingin dicapai dalam penelitian 
ini adalah untuk mengetahui dan menganalisis tingkat hubungan Pendidikan, Pertumbuhan Penduduk, dan Upah Minimum Kota dengan Pengangguran di Kabupaten Nunukan.

Penelitian ini diharapkan mempunyai kegunaan bersifat praktis yaitu:

a. Sebagai bahan pertimbangan dan masukan bagi pemerintah dalam upaya mengatasi pengangguran di Kabupaten Nunukan.

b. Sebagai bahan pembanding bagi penulis lain untuk meneliti masalah yang sama pada waktu dan daerah berbeda.

Penelitiaan ini diharapkan mempunyai kegunaan bersifat teoritis yaitu:

a. Untuk pengembangan keilmuan bidang pembelajaran ekonomi pembangunan.

b. Sebagai bahan referensi bagi pembaca dan penelitian selanjutnya.

\section{TINJAUAN PUSTAKA}

\section{Pengangguran}

Pengangguran adalah mereka yang tidak mempunyai pekerjaan dan sedang aktif mencari pekerjaan. Di atas usia 18 tahun masih sekolah dapat dikategorikan sebagai pengangguran (Putong, 2003).

$\underline{\text { Pendidikan }}$

Pendidikan adalah usaha sadar dan terencana untuk mewujudkan susana belajar dan proses pembelajaran agar peserta didik secara aktif mengembangkan potensi dirinya untuk memiliki kekuatan spiritual keagamaan, pengendalian diri, kepribadian, kecerdasan, akhlak mulia serta ketrampilan yang diperlukan dirinya dan masyarakat (Depdiknas, 2003).

$\underline{\text { Pertumbuhan Penduduk }}$

Pertumbuhan penduduk adalah perubahan jumlah penduduk di suatu wilayah tertentu pada waktu tertentu dibandingkan waktu sebelumnya. Semakin maraknya pertumbuhan penduduk di suatu wilayah maka akan semakin banyak pula masyarakat yang menganggur atau yang tidak mempunyai pekerjaan karena lapangan kerja yang tercipta tidak memenuhi syarat untuk jumlah penduduk yang semakin bertambah tiap tahunnya (Sadono Sukirno 2005).

\section{$\underline{\text { Upah Minimum Kota }}$}

Upah merupakan kompensasi yang diterima oleh satu unit tenaga kerja yang berupa jumlah uang yang dibayarkan kepadanya (Gregory Mankiw, 2003). Berdasarkan Peraturan Menteri Tenaga Kerja Nomor PER-01/MEN/1999, Upah Minimum Kabupaten/Kota (UMK) adalah upah minimum yang berlaku di daerah Kabupaten/Kota.

\section{$\underline{\text { Hipotesis }}$}

Diduga Pendidikan, Pertumbuhan Penduduk, dan Upah Minimum Kota memiliki hubungan sangat kuat dengan Pengangguran di Kabupaten Nunukan.

\section{$\underline{\text { Kerangka Penelitian }}$}

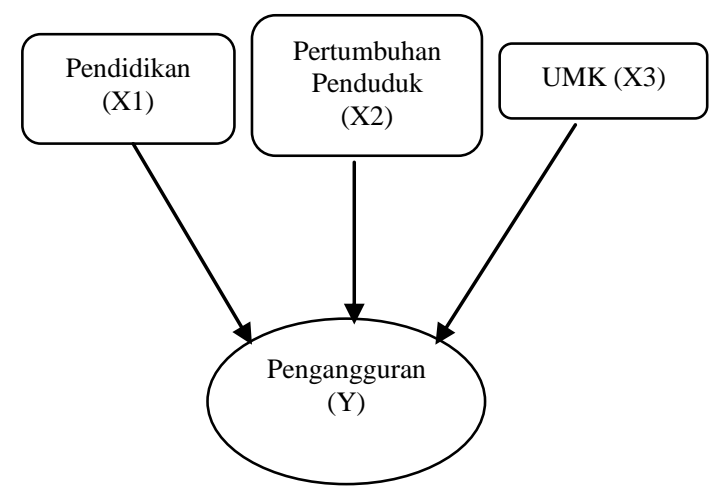

\section{METODE PENELITIAN}

Penelitian ini menggunakan pendekatan kuantitatif dengan metode studi pustaka, teknik pengumpulan data dengan mengadakan pengumpulan bahan referensi dari buku-buku, literatur, dan laporan yang dikeluarkan oleh instansi terkait. Penelitian ini dilaksanakan di 
Kabupaten Nunukan, dimana peneliti ingin mengetahui hubungan pengangguran dengan pendidikan, pertumbuhan penduduk, Upah Minimum Kota di Kabupaten Nunukan. Adapun waktu penelitian disini dilakukan bulan Januari 2017.

Jenis data yang digunakan dalam penelitian ini adalah data sekunder. J. Suprianto (2009), data sekunder adalah yang diperoleh dalam bentuk jadi dan telah diolah oleh pihak lain, yang biasanya dalam bentuk publikasi. Jadi data sekunder dalam penelitian ini berupa data angka pengangguran, pendidikan, pertumbuhan penduduk, dan upah minimum kota yang diambil dari Badan Pusat Statistik (BPS) Kabupaten Nunukan

Untuk melengkapi data dan referensi yang diperlukan dalam

penelitian ini, maka ditempuh cara sebagai berikut : Studi Kepustakaan (Library Research) artinya penelitian ini dilakukan dengan mengumpulkan teori dan data dari perpustakaan berupa buku-buku ilmiah, peraturan perundangundangan dan dokumen yang ada hubungannya dengan ruang lingkup penelitian ini, yang digunakan sebagai landasan pemikiran dan pembahasan serta berbagai jurnal penelitian, artikel, skripsi maupun hasil dari seminar. Studi Literatur artinya penelitian ini dilakukan mencari referensi teori yang relevan dengan kasus atau permasalahan yang ditemukan. Referensi ini dapat dicari dari buku, jurnal, artikel laporan penelitian dan situs-situs di internet. Output dari studi literatur ini adalah terkoleksinya referensi yang relevan dengan perumusan masalah.

Penelitian Dokumen atau dokumen research artinya penelitian terhadap seluruh dokumen atau arsip-arsip yang menyangkut data persentase Pendidikan, Pertumbuhan Penduduk, Upah Minimum Kota dan data Pengangguran tahun 20082015. Pada Badan Pusat Statistik (BPS) Kabupaten Nunukan. Adapun rincian data yang diperlukan dalam penelitian ini sebagai berikut :

1. Gambaran umum Kabupaten Nunukan.

2. Data Pengangguran di Kabupaten Nunukan selama periode tahun 2008 sampai 2015.

3. Data Pendidikan berdasarkan lama sekolah di Kabupaten Nunukan selama periode tahun 2008 sampai 2015.

4. Data Pertumbuhan Penduduk di Kabupaten Nunukan selama periode tahun 2008 sampai 2015

5. Data Upah Minimum Kota di Kabupaten Nunukan selama periode tahun 2008 sampai 2015.

Definisi operasional digunakan dalam penelitian ini agar dapat memudahkan dalam memahami alat analisis dari variabel-variabel yang digunakan dalam penyusunan penelitian ini, di antaranya: Pengangguran (Y), Pendidikan (X1), Pertumbuhan Penduduk (X2), dan Upah Minimum Kota (X3).

Metode Analisis Data

Menurut Nana sudjana (2007) Metode penelitian Korelasional

adalah studi korelasi yang mempelajari hubungan dua variabel atau lebih, yakni sejauh mana variasi dalam satu variabel berhubungan dalam variabel lain.

Untuk menggunakan analisis korelasi syarat utamanya adalah data linier dan berdistribusi normal, sedangkan syarat lainnya adalah tergantung dari tipe korelasi yang digunakan. Dalam penelitian ini untuk menjawab hipotesis yang telah ditentukan sebelumnya adalah menggunakan pearson correlation. Makna sifat korelasi:

Korelasi positif (+) berarti jika variabel $\mathrm{x}$ mengalami kenaikan maka variabel Y juga mengalami kenaikan . Korelasi negatif (-) berarti jika variabel $\mathrm{x}$ mengalami kenaikan maka variabel $Y$ akan mengalami penurunan,. 


\section{HASIL PENELITIAN}

Tujuan penggunaan analisis korelasi dalam penelitian ini adalah untuk mengetahui seberapa kuat atau besar hubungan antara pendidikan (X1), pertumbuhan penduduk (X2), Upah Minimum Kota (X3) terhadap tingkat pengangguran (Y) di Kabupaten Nunukan tahun 2008-2015. Maka koefisien korelasi yang diperoleh adalah sebagai berikut:

Tabel 1. Pearson Correlation

\begin{tabular}{|l|l|l|l|}
\hline & $\begin{array}{c}\text { Pendidik } \\
\text { an }\end{array}$ & $\begin{array}{c}\text { Pertumb } \\
\text { uhan } \\
\text { Pendudu } \\
\text { k }\end{array}$ & $\begin{array}{c}\text { Uopah } \\
\text { Minimjum } \\
\text { Kota }\end{array}$ \\
\hline $\begin{array}{l}\text { Pearso } \\
\mathrm{n} \\
\begin{array}{l}\text { Correl } \\
\text { ation }\end{array}\end{array}$ & -0.4733 & -0.28048 & -0.684778 \\
\hline
\end{tabular}

Sumber : Hasil Analisis, 2017

Korelasi (hubungan) antara pendidikan pada tahun 2008-2015 di Kabupaten Nunukan dengan tingkat pengangguran tahun 2008-2015 di Kabupaten Nunukan adalah -0.473394 dengan tingkat keeratan hubungan kategori cukup dan bentuk hubungannya adalah linier negatif. Ini memberikan pengertian bahwa variabel pendidikan memiliki hubungan yang cukup terhadap tingkat pengangguran tahun 2008-2015 di Kabupaten Nunukan. Dan apabila variabel pendidikan mengalami kenaikan maka variabel tingkat pengangguran akan mengalami penurunan dan sebaliknya. Pendidikan memiliki hubungan yang cukup dengan pengangguran disebabkan semakin meningkatnya kesadaran dan minat masyarakat di Kabupaten Nunukan tentang pentingnya pendidikan. Berdasarkan penelitian dahulu oleh AAIN Marhaeni tahun 2013, dimana pendidikan berpengaruh negatif terhadap jumlah pengangguran Kabupaten/Kota di Provinsi Bali.

Korelasi (hubungan) antara pertumbuhan penduduk pada tahun 20082015 di Kabupaten Nunukan dengan tingkat pengangguran tahun 2008-2015 di Kabupaten Nunukan adalah -0.280480 dengan tingkat keeratan hubungan kategori lemah dan bentuk hubungannya adalah linier negatif. Ini memberikan pengertian bahwa variabel pertumbuhan penduduk memiliki hubungan yang lemah terhadap tingkat pengangguran tahun 20082015 di Kabupaten Nunukan. Dan apabila variabel pertumbuhan penduduk mengalami kenaikan maka variabel tingkat pengangguran akan mengalami penurunan dan sebaliknya. Hal ini dikarenakan yang pertumbuhan penduduk yang makin meningkat diiringi dengan kesadaran masyarakat akan pentingnya pendidikan sebagai salah satu jalan untuk mendapatkan pekerjaan, juga memiliki skil untuk membuka usaha. Ketersediaan lapangan pekerjaan yang meningkat juga menjadi salah satu faktornya namun begitu masih banyak juga masyarakat Nunukan yang memilih untuk menjadi Tenaga Kerja Indonesia (TKI) karena merasa upah menjadi TKI tiga kali lebih besar dibanding kerja di Kabupaten Nunukan. Berdasarkan penelitian terdahulu oleh Syahrin Syam dan Abdul Wahab bertolak belakang dimana pertumbuhan penduduk berpengaruh positif dan signifikan terhadap pengangguran di Kota Makassar tahun 2001-2011.

Korelasi (hubungan) antara Upah Minimum Kota pada tahun 20082015 di Kabupaten Nunukan dengan tingkat pengangguran tahun 20082015 di Kabupaten Nunukan adalah -0.684778 dengan tingkat keeratan hubungan kategori kuat dan bentuk hubungannya adalah linier negatif. Ini memberikan pengertian bahwa variabel Upah Minimum Kota memiliki hubungan yang kuat terhadap tingkat pengangguran tahun 2008-2015 di Kabupaten Nunukan. Dan apabila variabel upah minimum kota mengalami kenaikan maka variabel tingkat pengangguran akan mengalami penurunan dan sebaliknya. Hal ini dikarenakan sertifikasi kompetensi pekerja yang dibarengi tingginya produktivitas yang dihasilkan serta semakin besar hasil kerja yang dilakukan, maka secara otomatis walaupun terjadi 
kenaikan upah, pekerja tidak langsung dirumahkan. Berdasarkan penelitian terdahulu oleh Nirmala Mansur, Daisy Engka dan Steva Tumangkeng tahun 2014, dimana Upah memberikan pengaruh negatif dan signifikan terhadap pengangguran di Manado.

\section{KESIMPULAN}

Berdasarkan analisis dan pembahasan yang telah diuraikan pada bab sebelumnya, maka penulis dapat menarik simpulan sebagai yaitu:

1. Hubungan antara pendidikan pada tahun 2008-2015 di Kabupaten Nunukan dengan tingkat pengangguran pada tahun 2008-2015 di Kabupaten Nunukan adalah negatif dan memiliki hubungan yang cukup.

2. Hubungan antara pertumbuhan penduduk pada tahun 2008-2015 di Kabupaten Nunukan dengan tingkat pengangguran pada tahun 2008-2015 di Kabupaten Nunukan adalah negatif dan memiliki hubungan yang kuat

3. Hubungan antara upah minimum kota pada tahun 2008-2015 di Kabupaen Nunukan dengan tingkat pengangguran pada tahun 2008-2015 di Kabupten Nunukan adalah negatif dan memiliki hubungan yang kuat.

\section{SARAN}

1. Kepada Pemerintah khususnya pemerintah Kabupaten Nunukan agar dalam menyusun perencanaan program terutama program pembangunan ekonomi dan sumber daya manusia tetap memberikan perhatian terhadap pengembangan sumber daya manusia baik upaya peningkatan kualitas fisik maupun non fisik. Kebijakan yang harus ditempuh dan dipertahankan Pemerintah serta didukung oleh masyarakat baik berupa perbaikan di bidang pendidikan dan pelatihan wirausaha.
2. Bagi pembaca ataupun masyarakat agar dapat memaksimalkan dan menggunakan dengan baik anggaran yang diberikan oleh pemerintah yaitu anggaran pendidikan dan wirausaha serta menggali potensi, keterampilan, dan skill yang dimiliki agar bisa berkontribusi terhadap kegiatan ekonomi. Peran masyarakat sangat penting diharapkan untuk lebih meningkatkan dan terlaksananya kebijakankebijakan pemerintah dengan cara meningkatkan etos kerja.

3. Bagi peneliti selanjutnya dengan topik sejenis disarankan untuk melakukan kajian lebih lanjut dengan memasukkan variabel independen lainnya. Serta memperpanjang periode penelitian, dan menggunakan alat analisis yang lebih akurat untuk mendapatkan hasil penelitian yang lebih mendekati fenomena sesungguhnya.

\section{DAFTAR PUSTAKA}

Aain Marheni 2013. Analisis Beberapa Faktor Yang Berpengaruh Terhadap Jumlah Pengangguran Kabupaten/Kota Di Provinsi Bali.

Badan Pusat Statistik Kabupaten Nunukan. 2017. Kabupaten Nunukan Dalam Angka 2008-2015

Boediono. 1993. Ekonomi Makro, Seri Sinopsis Pengantar Ilmu Ekonomi No 2 Edisi 4. Yogyakarta

Depnakertrans.2006.Penanggulangan di Indonesia, Majalah Nakertrans Edisi $03 \mathrm{Th}$

Mankiw, N Gregory. 2003. Teori Ekonomi Terjemahan. Jakarta: PT. Gramedia Pustaka Utama

Nirmala Mansur, Daisy Engka, Steve Tumangkeng 2014. Analisis Upah Terhadap Pengangguran Di Kota Manado Tahun 2003-2012.

Putong. 2003. Pengantar Ekonomi Mikro dan Makro Edisi II. Jakarta: Ghalian Indonesia. 
Sadono Sukirno. 2005. Pengantar Teori Ekonomi Makro. Jakarta: PT. Raja Grafinda Persada.

Syahrin Syam, Abdullah Wahab. 2013. Pengaruh Upah dan Pertumbuhan Penduduk Terhadap tingkat Pengangguran Di Kota Makassar. Undang - Undang Nomer 20 Tahun 2003 Tentang Pendidikan Nasional.

Tadaro, Michael P. 2000. Pembangunan

Ekonomi di Dunia.Jakarta:

Elangga. 
